\title{
Influence of Watchful Waiting on Satisfac- tion and Anxiety Among Patients Seeking Care for Unexplained Complaints
}

\author{
Marloes A. van Bokboven, MD, PbD ${ }^{1}$ \\ Hèlen Koch, MD, PbD \\ Trudy van der Weijden, $M D, P b D^{1}$ \\ Richard P. T. M. Grol, PbD ${ }^{1,3}$ \\ Arnold D. Kester, PbD \\ Paula E. L. M. Rinkens, BSc ${ }^{5}$ \\ Patrick J. E. Bindels, $M D, P b D^{2}$ \\ Geert-Jan Dinant, $M D, P b D^{6}$ \\ 'Department of General Practice/Centre \\ for Quality of Care Research, Maastricht \\ University, School for Public Health and \\ Primary Care (CAPHRI), Maastricht, \\ The Netherlands
}

${ }^{2}$ Department of General Practice, Academic Medical Center, University of Amsterdam, Division of Clinical Methods \& Public Health, Amsterdam, The Netherlands

${ }^{3}$ Centre for Quality of Care Research (WOK), Radboud University Nijmegen, Nijmegen, The Netherlands

${ }^{4}$ Department of Methodology and Statistics, Maastricht University, School for Public Health and Primary Care (CAPHRI), Maastricht, The Netherlands

${ }^{5}$ Centre for Data and Information Management, School for Public Health and Primary Care (CAPHRI), Maastricht University, Maastricht, The Netherlands

${ }^{6}$ Department of General Practice, School for Public Health and Primary Care (CAPHRI), Maastricht University, Maastricht, The Netherlands

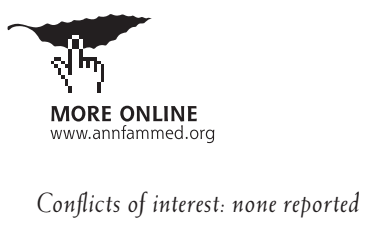

\section{CORRESPONDING AUTHOR}

Marloes A. van Bokhoven, MD, PhD

Maastricht University

Department of General Practice

PO Box 616

6200 MD Maastricht, The Netherlands

Loes.vanbokhoven@hag.unimaas.nl

\begin{abstract}
PURPOSE We undertook a study to determine whether test-ordering strategy and other consultation-related factors influence satisfaction with and anxiety after a consultation among patients seeking care for unexplained complaints.

METHODS A cluster-randomized clinical trial was conducted in family medicine practices in the Netherlands. Participants were 498 patients with unexplained complaints seen by 63 primary care physicians. Physicians either immediately ordered a blood test for patients or followed a 4-week watchful waiting approach. Physicians and patients completed questionnaires asking about their characteristics, satisfaction with care, and anxiety, and aspects of the consultation. The main outcomes were patient satisfaction and anxiety. Data were analyzed by multilevel logistic regression analysis.
\end{abstract}

RESULTS Patients were generally satisfied with their consultation and had moderately low anxiety afterward (mean scores on 11-point scales, 7.3 and 3.1, respectively), with no difference between the immediate testing and watchful waiting groups $\left(x^{2}=2.4\right.$ and 0.3 , respectively). The factors associated with higher odds of satisfaction were mainly related to physician-patient communication: patients' satisfaction with their physician generally, feeling taken seriously, and knowing the seriousness of complaints afterward; physicians' discussing testing and not considering complaints bearable; and older physician age. The same was true for factors associated with higher odds of anxiety: patients expecting testing or referral, patients not knowing the seriousness of their complaints afterward, and physicians not seeing a cause for alarm.

CONCLUSIONS Test-ordering strategy does not influence patients' satisfaction with and anxiety after a consultation. Instead, specific aspects of physicianpatient communication are important. Apparently, primary care physicians underestimate how much they can contribute to the well-being of their patients by discussing their worries.

Ann Fam Med 2009:7:112-120. DOI: 10.1370/afm.958.

\section{INTRODUCTION}

U

nexplained complaints in primary care can be defined as those complaints for which a primary care physician, after clarifying the reason for the encounter, taking the patient's history, and performing a physical examination, is unable to establish a diagnosis. ${ }^{1}$ Unexplained complaints are rather prevalent, especially in family medicine ${ }_{i}$ on average, $3 \%$ to $39 \%$ of consultations involve complaints considered to be unexplained by the primary care physician. ${ }^{2-5}$

In many cases, blood tests are ordered for these patients. Since testing in such situations is often superfluous from a diagnostic point of view, several strategies have been promoted to reduce the ordering of tests..$^{6-8}$ One of these strategies is to use a watchful waiting approach. ${ }^{1}$ 
So far, in the medical literature, this strategy has been used more in the treatment setting than in the diagnostic setting. ${ }^{9-11}$ In the context of unexplained complaints, which are usually self-limiting, this approach is thought to reduce the number of patients tested and to improve the predictive values of tests in patients tested after a watchful waiting period. ${ }^{12}$

Primary care physicians report, however, that they order tests for a variety of reasons other than diagnostic ones-an important one being patient requests. ${ }^{13,14}$ Patients often ask for tests, and primary care physicians feel that testing is an efficient way to reassure them. ${ }^{13-15}$ Satisfying and reassuring patients appear to be 2 important goals, especially in light of the long-term relationships between primary care physicians and patients, and the aim of preventing malpractice lawsuits. ${ }^{16,17}$ The literature shows that many patients do indeed expect blood tests to be ordered and have high expectations about the value of such tests. ${ }^{3,18,19}$ Their satisfaction with the care they receive may largely depend on such testing. It remains unclear whether testing does indeed influence patients' satisfaction with care, however. Some studies show that patients place greater importance on alternate aspects of care, such as being listened to and getting a clear explanation about the nature of their problem. ${ }^{20,21}$ In other studies, patients have stated that they would be very dissatisfied if their expectations were not met. ${ }^{18,22-24}$ None of these studies specifically looked at unexplained complaints, however.

The literature provides little support for patient reassurance as a reason for ordering tests. Qualitative studies have shown that patients may be uncomfortable with clinical uncertainty, and that they expect to obtain definitive information about their health from test results. ${ }^{18,22}$ Reassurance is recognized as an important aspect of the physician-patient relationship, which in turn is a dimension of patient satisfaction. ${ }^{25,26}$ A review of the concepts of patient satisfaction concluded, however, that a direct association of reassurance with satisfaction remains unproven. ${ }^{27}$

In summary, whereas reducing superfluous testing by using a watchful waiting approach seems a matter of rational decision making, it remains questionable if this approach is acceptable to patients. We hypothesized that watchful waiting would decrease patient satisfaction and increase patient anxiety.

The purpose of this study was to determine whether immediate test ordering, compared with watchful waiting, influences satisfaction with and anxiety after the consultation among patients seeking care for unexplained complaints. We also wanted to assess the relationship between the test-ordering strategy and other characteristics of the primary care physician and practice, the patient, and the complaints and consultation.

\section{METHODS \\ Design}

The study was part of a cluster-randomized clinical trial on blood test ordering among patients with unexplained complaints, using the primary care physicians' practices as the level of randomization. Participating family practices were randomly assigned to 3 groups using a computer-generated blockwise randomization list (Figure 1). Primary care physicians in Group 1 were instructed to order blood tests immediately at the first consultation. Those in Group 2 were instructed to propose a 4 -week watchful waiting approach to their patients. Those in Group 3 were also instructed to try to postpone test ordering, but at the same time, they participated in a quality improvement initiative that supported them in postponing test ordering for patients with unexplained complaints. The quality improvement initiative had been systematically developed, based on barriers to and facilitators of blood test ordering identified among primary care physicians and patients. It consisted of 2 small-group meetings and a practice visit. The full protocol of this trial, addressing all criteria for the reporting of randomized clinical trials - a Consolidated Standards of Reporting Trials (CONSORT) statement-has been published elsewhere. ${ }^{28}$ The medical ethics committees of both the Academic Medical Center-University of Amsterdam and the University Hospital Maastricht approved the trial.

\section{Setting and Participants}

The trial took place in family medicine practices in the southern and western provinces of the Netherlands. Both single-physician and group practices could participate.

Patients were eligible to participate if they were aged 18 years or older and sought care for a complaint that remained unexplained after history taking and physical examination, according to their primary care physician. All patients were registered with a family practice. We restricted eligibility to patients with any of 5 types of complaints: fatigue, abdominal complaints, musculoskeletal complaints, weight change, or pruritus. We selected these complaints because they have a high prevalence in primary care and are frequently considered unexplained initially. Another requirement was that blood test ordering might add to the diagnosis. Patients also had to be able to read, speak, and understand Dutch. We excluded patients whose unexplained complaints alarmed the primary care physician, making watchful waiting unacceptable. Also excluded were patients who had sought care for an unexplained complaint within 6 months before the consultation.

The primary care physicians were asked to invite each consecutive eligible patient to enroll in the trial. 


\section{Figure 1. Randomization scheme, numbers of participants, and questionnaires used.}

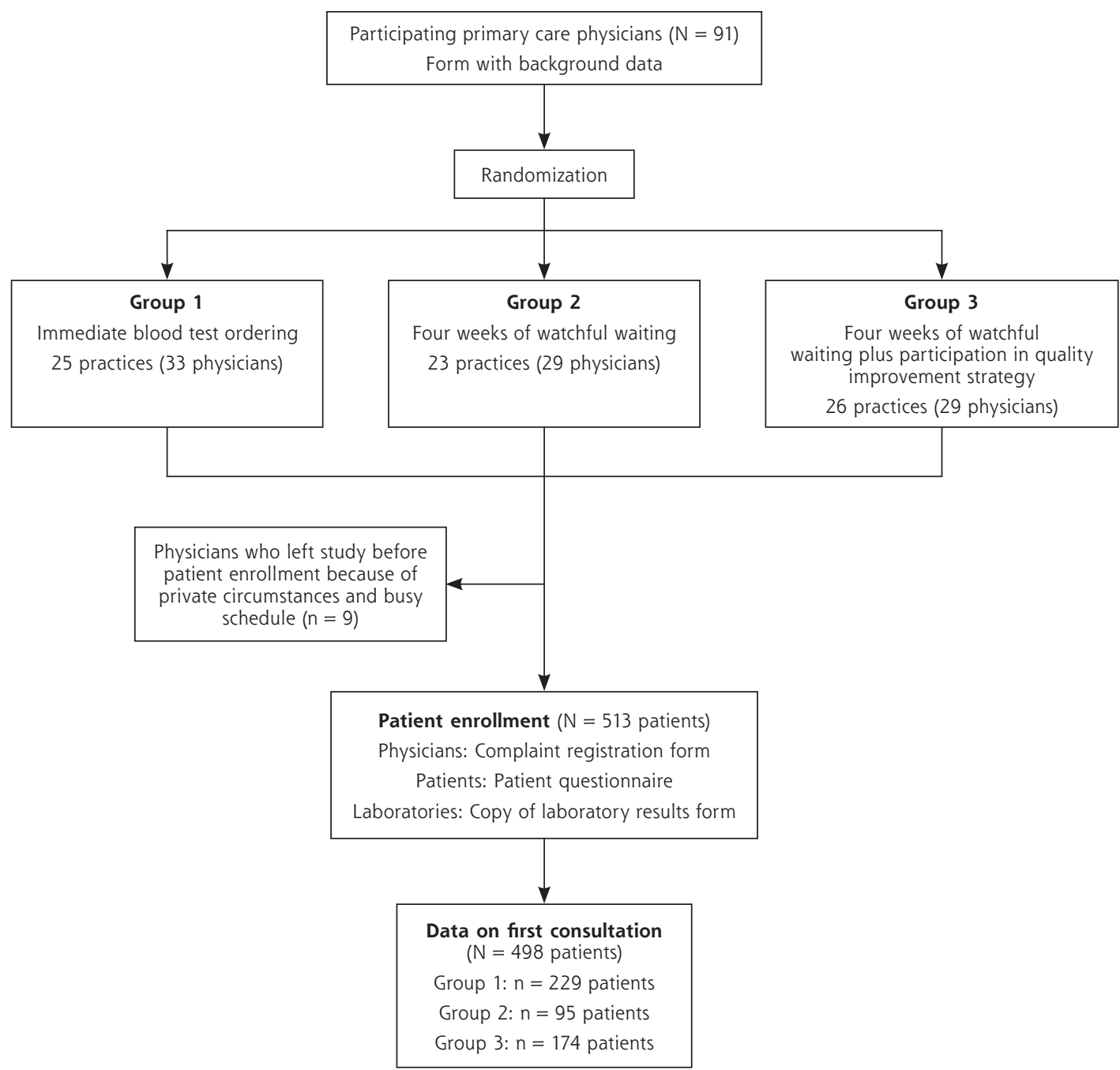

They gave the patients written information and asked them to provide informed consent. All patients were told that different diagnostic strategies were being evaluated. Those in the immediate test-ordering group were told that their physician might order blood tests. Those in the watchful waiting groups were kept naive about the possibility of blood test ordering to prevent a Hawthorne effect.

\section{Measures}

The data analyzed for this paper were derived from the consultation at which a patient was enrolled in the trial. The variables studied are summarized in Table 1 . We collected data about the characteristics of the primary care physician and practice, the patient, the complaint, and the consultation. Participating primary care physicians completed a form asking about their characteristics after they had agreed to participate. When a patient was enrolled in the study, the primary care physician filled in a complaint registration form, and the patient was given a questionnaire to take home, complete, and return to the research group immediately after the consultation, in a stamped envelope. When blood tests were ordered, a copy of the test results form was sent directly to the research group by the laboratory facility.

Patients' satisfaction with and anxiety after their consultation were measured with 2 questions: "How satisfied are you about the visit that you just paid to the primary care physician?" and "How anxious are you after the visit you just paid to the primary care physician?" For both questions, possible responses ranged from 0 (dissatisfaction or no anxiety) to 10 (total satisfaction or extreme anxiety). Patients were also asked after their consultation about their general satisfaction with the primary care physician and their anxiety 


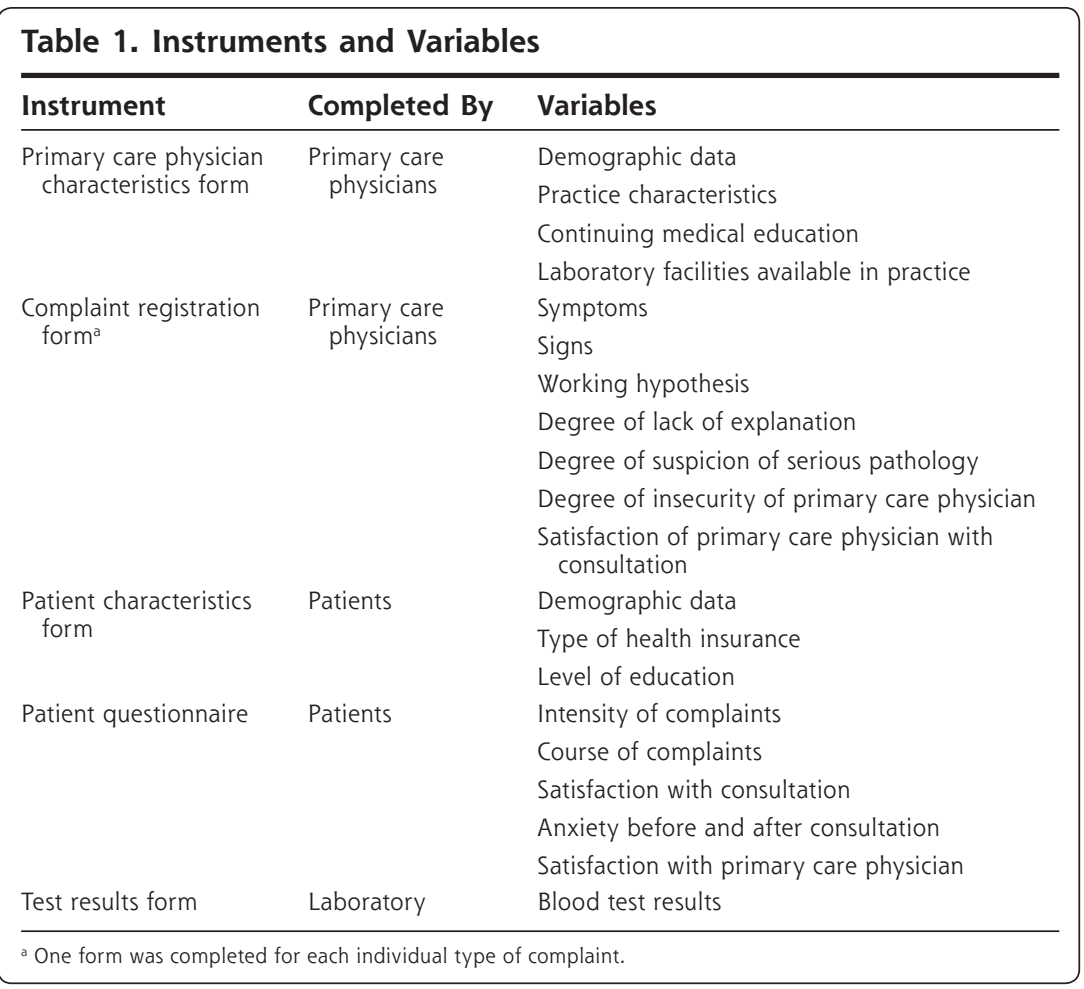

before the consultation (also rated on scales ranging from 0 to 10). The latter was assessed by asking the patients to imagine the moment they were in the waiting room before the consultation and remember how anxious they had felt at that time.

\section{Statistical Analysis}

Except for randomization and duration of complaints, we dichotomized variables, using the mean or the median, where appropriate (as detailed in the supplemental tables, available online-only at http://www.annfammed.

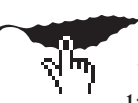

org/cgi/content/full/7/2/112/DC1). Patient satisfac-

tion and anxiety were dichotomized because of their distinctly nonnormal distribution, and patients were defined as being satisfied or as having anxiety if they had an above-mean score for the measure.

Level of satisfaction with and anxiety after the consultation were determined both for each randomization group and overall. We also analyzed the relation between the ordering of tests and satisfaction or anxiety.

We performed bivariate analyses using patient satisfaction with the consultation and patient anxiety after the consultation as the dependent variables, and randomization group and the characteristics of the primary care physician and practice, the patient, the complaints, and the consultation as the independent variables. This analysis was conducted using the SPSS 11 statistical software package (SPSS Inc, Chicago, Illinois).

We entered independent variables having a bivariate $P$ value of .1 or less in a backwards multilevel logistic regression analysis to correct for possible confounding, using the Stata 8 statistical software package (Stata Corp, College Station, Texas). We used a random intercept for the practice level and retained randomization group in the model. Subsequently, we added variables that might influence satisfaction and anxiety, and repeated the analysis. Results are presented as adjusted odds ratios (ORs) and 95\% confidence intervals (CIs).

\section{RESULTS \\ Participants' Flow and Characteristics}

Enrollment took place from February 2002 until December 2003. In total, 91 primary care physicians were randomized in the trial, 9 of whom ended their participation before enrollment of patients started, mainly because of personal circumstances and a busy practice schedule; an additional 19 did not enroll any patients. In the end, 63 primary care physicians enrolled 513 patients.

Data about the first consultation were available for 498 patients (Figure 1). The baseline characteristics of physicians and patients are summarized in Tables 2 and 3 , respectively. The mean age of the participating primary care physicians was 45 years (SD, 7.3), and $74 \%$ were male. They had a mean of 13 years of experience (SD, 8.7). The mean age of the patients was 43 years $(\mathrm{SD}, 16.2)$, and $28 \%$ were male.

\section{Satisfaction and Anxiety}

As shown in Table 4, the mean satisfaction score of patients with the consultation on the scale from 0 to 10 was 7.3 (SD, 2.0). The mean anxiety score after the consultation was 3.1 (SD, 2.5). We found no significant differences between the 3 randomization groups in satisfaction and anxiety scores; furthermore, satisfaction did not differ significantly according to whether blood tests were ordered (described below). Multivariate analysis did not identify any confounders.

\section{Relation of Laboratory Test Ordering and Patient Satisfaction or Anxiety}

The Supplemental Tables 1 and 2 summarize determinants of satisfaction and anxiety that were significant 
Table 2. Characteristics of Physicians $(\mathrm{N}=91)$

\begin{tabular}{|c|c|c|c|c|}
\hline \multirow[b]{2}{*}{ Characteristic } & \multirow[b]{2}{*}{$\begin{array}{c}\text { Total } \\
\text { Sample } \\
(\mathrm{N}=91)\end{array}$} & \multicolumn{3}{|c|}{ Group } \\
\hline & & $\begin{array}{l}\text { Immediate } \\
\text { Test Ordering } \\
(n=33)\end{array}$ & $\begin{array}{l}\text { Watchful } \\
\text { Waiting } \\
(n=29)\end{array}$ & $\begin{array}{l}\text { Watchful } \\
\text { Waiting + QI } \\
(n=29)\end{array}$ \\
\hline Age, mean (SD), years & $45(7.3)$ & $47(5.8)$ & $44(7.2)$ & $45(8.8)$ \\
\hline Sex, No. (\%) male & $67(74)$ & $26(79)$ & $17(59)$ & $24(83)$ \\
\hline $\begin{array}{l}\text { Experience as a primary care } \\
\text { physician, mean (SD), years }\end{array}$ & $13(8.7)$ & $14(7.1)$ & $11(8.4)$ & $14(10.4)$ \\
\hline Practice type, No. (\%) solo & $34(37)$ & $9(27)$ & $15(52)$ & $10(34)$ \\
\hline $\begin{array}{l}\text { Practice region, No. (\%) in } \\
\text { western region }\end{array}$ & $44(48)$ & $19(58)$ & $11(38)$ & $14(48)$ \\
\hline \multicolumn{5}{|l|}{ Practice location, No. (\%) } \\
\hline Urban & $45(50)$ & $15(47)$ & $15(52)$ & $15(52)$ \\
\hline Semirural & $11(12)$ & $4(13)$ & $5(17)$ & $2(7)$ \\
\hline Rural & $34(38)$ & $13(41)$ & $9(31)$ & $12(41)$ \\
\hline $\begin{array}{l}\text { Number of topics done } \\
\text { during CME, mean (SD) }\end{array}$ & $1.9(1.6)$ & $1.9(1.6)$ & $2.3(1.1)$ & $1.5(1.6)$ \\
\hline $\begin{array}{l}\text { Number of available labora- } \\
\text { tory tests in own practice, } \\
\text { mean (SD) }\end{array}$ & $2.4(1.1)$ & $2.4(1.2)$ & $1.9(1.0)$ & $2.6(0.9)$ \\
\hline
\end{tabular}

Table 3. Characteristics of Patients $(\mathrm{N}=498)$

\begin{tabular}{|c|c|c|c|c|}
\hline \multirow[b]{2}{*}{ Characteristic } & \multirow[b]{2}{*}{$\begin{array}{c}\text { Total } \\
\text { Sample } \\
(\mathrm{N}=498)\end{array}$} & \multicolumn{3}{|c|}{ Group } \\
\hline & & $\begin{array}{c}\text { Immediate } \\
\text { Test Ordering } \\
(n=229)\end{array}$ & $\begin{array}{l}\text { Watchful } \\
\text { Waiting } \\
(n=95)\end{array}$ & $\begin{array}{c}\text { Watchful } \\
\text { Waiting }+ \text { QI } \\
(n=174)\end{array}$ \\
\hline Age, mean (SD), years & $43(16.2)$ & $42(15.5)$ & $45(15.2)$ & $45(17.5)$ \\
\hline Sex, No. (\%) male & $140(28)$ & $67(29)$ & $18(19)$ & $55(32)$ \\
\hline $\begin{array}{l}\text { Type of health insurance, } \\
\text { No. (\%) with private }\end{array}$ & $164(34)$ & $80(35)$ & $37(39)$ & $47(27)$ \\
\hline \multicolumn{5}{|l|}{$\begin{array}{l}\text { Highest level of education } \\
\text { completed, No. (\%) }\end{array}$} \\
\hline None & $4(1)$ & $2(1)$ & $1(1)$ & $1(1)$ \\
\hline Primary & $46(10)$ & $20(9)$ & $5(5)$ & $21(12)$ \\
\hline Secondary & $323(67)$ & $146(64)$ & $65(68)$ & $112(64)$ \\
\hline Higher & $106(22)$ & $55(24)$ & $21(22)$ & $30(17)$ \\
\hline
\end{tabular}

QI = quality improvement.

Note: Percentages may not total to ! $00 \%$ because of rounding and missing data for a few patients. a Vs compulsory.

\section{Table 4. Patients' Satisfaction With and Anxiety After} the Consultation

\begin{tabular}{|c|c|c|c|c|}
\hline \multirow[b]{2}{*}{ Measure } & \multirow[b]{2}{*}{$\begin{array}{c}\text { Total } \\
\text { Sample } \\
(\mathbf{N}=498)\end{array}$} & \multicolumn{3}{|c|}{ Group } \\
\hline & & $\begin{array}{l}\text { Immediate } \\
\text { Test Ordering } \\
(n=229)\end{array}$ & $\begin{array}{l}\text { Watchful } \\
\text { Waiting } \\
(n=95)\end{array}$ & $\begin{array}{c}\text { Watchful } \\
\text { Waiting + QI } \\
(n=174)\end{array}$ \\
\hline $\begin{array}{l}\text { Satisfaction, mean } \\
\text { (SD) score }\end{array}$ & $7.3(2.0)$ & $7.4(2.1)$ & $7.4(1.9)$ & $7.1(2.1)$ \\
\hline $\begin{array}{l}\text { Anxiety, mean } \\
\text { (SD) score }\end{array}$ & $3.1(2.5)$ & $3.1(2.5)$ & $3.4(2.7)$ & $2.8(2.4)$ \\
\hline
\end{tabular}

at $P$ of .1 or less in the bivariate analysis. Satisfaction did not differ significantly across the 3 study groups having different test-ordering strategies $\left(\chi^{2}=2.4\right)$ or between patients for whom laboratory tests were and were not actually ordered, as determined by receipt of the test results form $(\mathrm{OR}=1.3 ; 95 \% \mathrm{CI}$, 0.9-1.8). The same was true for patient anxiety with regard to study group $\left(\chi^{2}=0.3\right)$ and the ordering of tests $(\mathrm{OR}=1.2 ; 95 \%$ CI, 0.9-1.6).

\section{Determinants of Patient Satisfaction and Anxiety} Adjusted odd ratios for associations between various factors and patient satisfaction and anxiety in the multivariate analyses are shown in Tables 5 and 6 , respectively. These analyses retained study group $(1,2$, or 3$)$ in the model, but it was of limited influence. The intracluster correlation coefficient of the practice level was low for both satisfaction and anxiety, indicating that randomization at the practice level did not cause bias in outcomes at the patient level.

Patients with unexplained complaints were more likely to be satisfied with their consultation when they were satisfied with their primary care physician in general $(\mathrm{OR}=14.39)$, when they felt they had been taken seriously $(\mathrm{OR}=7.56)$, when, in their opinion, the physician had discussed laboratory testing with them $(\mathrm{OR}=2.28)$, and when they thought they knew how serious their complaints were after the consultation $(\mathrm{OR}=2.07)$. They were less likely to be satisfied when their physician was younger $(\mathrm{OR}=0.47)$ and when their physician thought the complaints were bearable $(\mathrm{OR}=0.30)$.

Patients were more likely 


\begin{tabular}{|c|c|}
\hline Variable & $\begin{array}{l}\text { Adjusted } \\
\text { Odds Ratio } \\
(95 \% \mathrm{Cl})\end{array}$ \\
\hline \multicolumn{2}{|l|}{ Group } \\
\hline Immediate test ordering & 1.00 (ref) \\
\hline Watchful waiting & $0.84(0.39-1.82)$ \\
\hline Watchful waiting + QI & $0.91(0.48-1.72)$ \\
\hline \multicolumn{2}{|c|}{ Patient was generally satisfied with physician } \\
\hline Yes & $14.39(7.63-27.14)$ \\
\hline No & 1.00 (ref) \\
\hline \multicolumn{2}{|l|}{ Patient felt taken seriously } \\
\hline Yes & $7.56(1.88-30.36)$ \\
\hline No or unknown & 1.00 (ref) \\
\hline \multicolumn{2}{|c|}{$\begin{array}{l}\text { Physician discussed laboratory testing with } \\
\text { patient, according to patient }\end{array}$} \\
\hline Yes & $2.28(1.28-4.07)$ \\
\hline No or unknown & 1.00 (ref) \\
\hline \multicolumn{2}{|c|}{$\begin{array}{l}\text { Patient knew seriousness of complaints after } \\
\text { the consultation, according to patient }\end{array}$} \\
\hline Yes & $2.07(1.18-3.63)$ \\
\hline No & 1.00 (ref) \\
\hline \multicolumn{2}{|l|}{ Age of physician } \\
\hline$\leq 46$ years & $0.47(0.26-0.84)$ \\
\hline$>46$ years & 1.00 (ref) \\
\hline \multicolumn{2}{|c|}{ Physician considered complaints bearable } \\
\hline Yes & $0.30(0.11-0.78)$ \\
\hline No & 1.00 (ref) \\
\hline \multicolumn{2}{|c|}{$\mathrm{Cl}=$ confidence interval; ref = reference group; $\mathrm{QI}=$ quality improvement. } \\
\hline \multicolumn{2}{|c|}{$\begin{array}{l}\text { Notes: Detailed definitions for each category are given in the supplemental } \\
\text { tables. Group was retained in the model using } 2 \text { dummy variables. The intra- } \\
\text { cluster correlation coefficient was } 2.37 \mathrm{e}^{-7} \text {. }\end{array}$} \\
\hline
\end{tabular}

to have anxiety after the consultation when they had already been anxious before the consultation $(\mathrm{OR}=6.83)$, when they expected to be referred to a specialist $(\mathrm{OR}=2.64)$ or expected blood tests to be ordered $(\mathrm{OR}=1.84)$, and when the physician did a physical examination during the consultation $(\mathrm{OR}=2.03)$. They were also more likely to have anxiety when the physician felt certain that there was no cause for alarm $(\mathrm{OR}=2.37)$ or took a special interest in psychosocial and unexplained complaints $(\mathrm{OR}=2.21)$. On the other hand, they were less likely to be anxious when they themselves considered their complaints bearable $(\mathrm{OR}=0.56)$, when they felt satisfied with the consultation $(\mathrm{OR}=0.53)$, and when they thought they knew how serious their complaints were after the consultation $(\mathrm{OR}=0.45)$.

We also assessed the presence of interaction terms. Study group may have interacted with the patient's perception of being taken seriously, but further statistical analysis was impossible because of the small number of patients in one subgroup.
Table 6. Odds of Patient Anxiety After the Consultation in the Multivariate, Multilevel Logistic Regression Analysis

\begin{tabular}{|c|c|}
\hline Variable & $\begin{array}{c}\text { Adjusted } \\
\text { Odds Ratio } \\
(95 \% \mathrm{Cl})\end{array}$ \\
\hline \multicolumn{2}{|l|}{ Group } \\
\hline Immediate test ordering & 1.00 (ref) \\
\hline Watchful waiting & $2.25(1.09-4.60)$ \\
\hline Watchful waiting + QI & $1.12(0.64-1.97)$ \\
\hline \multicolumn{2}{|c|}{ Patient had anxiety before the consultation } \\
\hline Yes & $6.83(4.15-11.25)$ \\
\hline No & 1.00 (ref) \\
\hline \multicolumn{2}{|c|}{ Patient expected referral to a specialist } \\
\hline Yes & $2.64(1.52-4.57)$ \\
\hline No or did not care & 1.00 (ref) \\
\hline \multicolumn{2}{|c|}{$\begin{array}{l}\text { Physician felt certain that there was no cause } \\
\text { for alarm }\end{array}$} \\
\hline Yes & $2.37(1.02-5.51)$ \\
\hline No & 1.00 (ref) \\
\hline \multicolumn{2}{|c|}{$\begin{array}{l}\text { Physician took a special interest in psychiatry, } \\
\text { psychosomatics, or unexplained complaints }\end{array}$} \\
\hline Yes & $2.21(1.13-4.31)$ \\
\hline No & 1.00 (ref) \\
\hline \multicolumn{2}{|c|}{ Physician performed physical examination } \\
\hline Yes & $2.03(1.11-3.72)$ \\
\hline No & 1.00 (ref) \\
\hline \multicolumn{2}{|c|}{ Patient expected blood tests to be ordered } \\
\hline Yes & $1.84(1.07-3.20)$ \\
\hline No or unknown & 1.00 (ref) \\
\hline \multicolumn{2}{|c|}{ Patient considered complaints bearable } \\
\hline Yes & $0.56(0.32-0.97)$ \\
\hline No & 1.00 (ref) \\
\hline \multicolumn{2}{|c|}{ Patient was satisfied with the consultation } \\
\hline Yes & $0.53(0.32-0.88)$ \\
\hline No & 1.00 (ref) \\
\hline \multicolumn{2}{|c|}{$\begin{array}{l}\text { Patient knew seriousness of complaints after } \\
\text { the consultation, according to patient }\end{array}$} \\
\hline Yes & $0.45(0.25-0.79)$ \\
\hline No & 1.00 (ref) \\
\hline \multicolumn{2}{|c|}{$\mathrm{Cl}=$ confidence interval; ref = reference group; $\mathrm{QI}=$ quality improvement. } \\
\hline \multicolumn{2}{|c|}{$\begin{array}{l}\text { Notes: Detailed definitions for each category are given in the supplemental } \\
\text { tables. Group was retained in the model using } 2 \text { dummy variables. The intra- } \\
\text { cluster correlation coefficient was } 2.53 \mathrm{e}^{-7} \text {. }\end{array}$} \\
\hline
\end{tabular}

\section{DISCUSSION}

This study did not confirm our hypothesis that a watchful waiting approach in ordering tests for patients with unexplained complaints would decrease patient satisfaction and increase patient anxiety. The test-ordering strategy did not appear to be related to either of these outcomes. Instead, specific aspects of physician-patient communication tended to be more important determinants of these outcomes.

The finding that satisfaction with the consultation was closely related to patients' satisfaction with their primary care physician in general is in agreement with 
the literature on the concept of satisfaction. ${ }^{27}$ The literature shows mixed results concerning the influence of the age of the primary care physician on satisfaction, ${ }^{29-31}$ with both younger and older age reported to be related to greater patient satisfaction. Three other determinants of satisfaction-patients feeling they were taken seriously, physicians discussing testing, and patients knowing the seriousness of their complaints after the consultation-mainly concern aspects of communication. It has been previously recognized that communication is important for patient satisfaction. ${ }^{27,32}$

Primary care physicians tend to overestimate how bearable patients' unexplained complaints are, which might explain why some patients do not feel taken seriously. Although there is a tendency to view unexplained complaints of recent origin as mild and self-limiting, because patients frequently do not return to their primary care physicians for the complaints, this view may be incorrect, as longitudinal analyses from this trial show that such patients' quality of life tends to remain low, even after a year. ${ }^{12,33}$ Patients with unexplained complaints frequently do not feel that they have been taken seriously, because they get the impression that physicians think they are faking their complaints. ${ }^{34}$ It might be useful for primary care physicians in daily practice to ask patients how bearable their symptoms are and to check whether patients feel that they know how serious their complaints are at the end of the consultation.

Although we did not find any related evidence in the literature, it seems obvious to us that anxiety before the consultation influences anxiety afterward. The negative influence of a physical examination on patient anxiety is not so easy to explain. The usual advice for unexplained complaints is to do a physical examination to show that a patient is being taken seriously. ${ }^{35}$ Proper evidence for this advice is currently lacking, however. An alternative explanation is that primary care physicians recognize anxious patients and apply physical examination especially to this group, in order to reassure them, probably with limited effect. A third possible explanation is that patients usually do not expect to be examined and that, when they are, they view this as an alarm signal; however, in our study, anxiety before the consultation did not differ between patients who had expected physical examination and patients who had not.

As for the determinants of satisfaction, many of the determinants of anxiety were related to aspects of communication. A patient's expectation that blood tests would be ordered, as well as their wish to be referred to a specialist, could be a signal to the primary care physician to explore anxiety. In addition, as for satisfaction, physicians' views about how alarm- ing complaints are do not always seem to correspond with those of their patients. The final determinant that was associated with higher levels of anxiety, namely, whether the physician took a special interest in psychiatry, psychosomatics, or unexplained complaints, was surprising to us. Our explanation for this finding is that physicians with such a special interest may tend to focus on the role of psychosocial factors in unexplained complaints. In the early stages of unexplained complaints, patients might then feel that insufficient attention is being given to the somatic aspects of their complaints. The literature shows that physicians' explanations are frequently at odds with the patients' own thinking. ${ }^{36}$ Although patients are prepared to accept a psychosocial cause of their complaints, it is important to address their concerns, confirm the reality of their complaints, and link physical and psychological factors. ${ }^{37-39}$ Exploring how bearable complaints are, as well as patients' feelings about the seriousness of their complaints and the nature of their concerns, may decrease their anxiety.

Because of the finding that test-ordering strategy did not influence patient satisfaction and anxiety, we checked whether the study had sufficient statistical power. We considered a difference of 1 point (on the scale of $0-10$ points) in satisfaction the minimum clinically relevant difference between the groups. With $\alpha=.05$ and $\beta=.90$, each group needed to consist of 62 patients. With 95 to 229 patients in each group, our groups were of sufficient size.

The data for this study were collected in Dutch family practices. As is typical of Dutch family medicine, patients are registered to a practice (list system), and thus doctors and patients build long-term relationships. In addition, diagnostic testing and prescribing are relatively uncommon in family medicine in the Netherlands, compared with other countries. One explanation may be that Dutch primary care physicians are not paid for ordering diagnostic procedures. They receive a capitation fee per listed patient plus a smaller fee for service, which is not influenced by diagnostic procedures. A second explanation is that the need to practice defensive medicine in order to prevent lawsuits is not very high in the Netherlands, because every patient has health insurance that covers almost all medical costs in primary care and the hospital. A third explanation may be that in the Netherlands, guidelines have been developed that include recommendations about the ordering of diagnostic tests. The guidelines are developed by primary care physicians and are highly esteemed among the professional group. A fourth explanation may be that Dutch primary care physicians are more prepared to take risks than physicians from some other countries. ${ }^{40}$ Primary care physi- 
cians state that patient preferences strongly influence their diagnostic behaviors, however. Dutch patients, for their part, have high expectations that blood tests will clarify health issues. ${ }^{18}$ They prefer 1,000 patients to be tested superfluously if this can prevent missing serious disease in a single patient. ${ }^{41}$ In that respect, Dutch patients do not differ much from their American counterparts, so we expect that our results are generalizable to the US patient population.

A strength of this study is that we used real consultations instead of hypothetical situations to assess patients' views about the consultation, and also included characteristics of the physician and consultation in the analysis, as usually, only patients' opinions are taken into account. A limitation of the study was that satisfaction with the consultation and anxiety before the consultation were measured after the consultation. This approach may have caused some bias. It was not possible to measure these outcomes earlier, however, because it was not clear if the patients had unexplained complaints (and hence were eligible for the study) until the family physicians diagnosed them. We tried to overcome this limitation by asking the patients to recall the moment they were in the waiting room before the consultation, before asking the other research questions. In addition, we placed the questions about satisfaction with the consultation and anxiety after the consultation at the end of the questionnaire.

Another limitation of the study was that selective inclusion of patients may have caused bias. The physicians in the watchful waiting-only group enrolled fewer patients than the physicians in the other groups. This difference seems to have been due to the number of physicians in this group who did not enroll any patients in the study. If these physicians are left out of the analysis, no statistically significant difference in patient enrollment between the groups remains. Our explanation is that these physicians hesitated to ask patients to participate because they did not have any extra diagnostic tests to offer them that could serve as a "reward" for participation. If this were indeed the case, physicians in botb watchful waiting groups should have enrolled fewer patients. But physicians in the watchful waiting group with the added quality improvement initiative had participated in training sessions in which they discussed the limited value of immediate test ordering and the effects of watchful waiting. Physicians in that group may therefore have felt more confident about convincing patients to participate. Although we have no indications of selective inclusion, we cannot completely exclude it either.

Our study shows that ordering blood tests for patients with unexplained complaints is not related to the patients' satisfaction and anxiety, and thus, that these patients do not differ much in this respect from a more general patient population. ${ }^{19,31}$ This finding is especially remarkable as patient satisfaction and anxiety are important factors in primary care physicians' decisions about ordering tests. Apparently, primary care physicians overestimate the effects of additional testing in patients seeking care for unexplained complaints and underestimate how much they themselves can contribute to the well-being of their patients by discussing their worries.

To read or post commentaries in response to this article, see it online at http://www.annfammed.org/cgi/content/full/7/2/112.

Key words: Outcome assessment (health care); physician-patient relations; laboratory techniques and procedures; patient satisfaction; family practice; primary care; practice-based research

Submitted April 1, 2008; submitted, revised, July 28, 2008; accepted August 5, 2008.

Results of this study were presented in part at the 26th European Conference on Psychosomatic Research, September 27-30, 2006, Cavtat, Dubrovnik, Croatia.

Funding support: This study was funded by the Dutch College of Health Care Insurances (CVZ). Supplementary financial support was provided by the Centraal Ziekenfonds (CZ) health insurance company, the Netherlands Organization for Scientific Research (NWO), the "De Drie Lichten" foundation, the Foundation for Public Health and Smoking (STIVORO), and the Netherlands Heart Foundation. None of the agencies funding the study influenced the study design, the writing of the manuscript, or the decision to submit the manuscript for publication.

Trial Registry Number: ISRCTN55755886.

\section{References}

1. Dinant G-J, van Wijk MAM, Janssens HJEM, et al. NHG-standaard bloedonderzoek. Algemene principes en uitvoering in eigen beheer [Dutch College of General Practitioners guideline "Blood testing." General principles and use under direct management]. Huisarts Wet. 1994;37(5):202-211.

2. Peveler R, Kilkenny L, Kinmonth A-L. Medically unexplained physical symptoms in primary care: a comparison of self-report screening questionnaires and clinical opinion. J Psychosom Res. 1997;42(3):245-252.

3. van der Weijden T, van Velsen M, Dinant GJ, van Hasselt CM, Grol RPTM. Unexplained complaints in general practice. Prevalence, patients' expectations, and professionals' test-ordering behavior. Med Decis Making. 2003;23(3):226-231.

4. Burton C. Beyond somatisation: a review of the understanding and treatment of medically unexplained physical symptoms (MUPS). $\mathrm{Br}$ J Gen Pract. 2003;53(488):231-241.

5. Feder A, Olfson M, Gameroff M, et al. Medically unexplained symptoms in an urban general medicine practice. Psychosomatics. 2001;42(3):261-268.

6. Hindmarsh JT, Lyon AW. Strategies to promote rational clinical chemistry test utilization. Clin Biochem. 1996;29(4):291-299.

7. Winkens R, Dinant G-J. Evidence base of clinical diagnosis: rational, cost effective use of investigations in clinical practice. BMJ. 2002;324(7340):783-785. 
8. Solomon $\mathrm{DH}$, Hashimoto $\mathrm{H}$, Daltroy L, Liang MH. Techniques to improve physicians' use of diagnostic tests: a new conceptual framework. JAMA. 1998;280(23):2020-2027.

9. Little P, Gould C, Williamson I, Moore M, Warner G, Dunleavy J. Pragmatic randomised controlled trial of two prescribing strategies for childhood acute otitis media. BMJ. 2001;322(7282):336-342.

10. Arroll B, Kenealy T, Kerse N. Do delayed prescriptions reduce antibiotic use in respiratory tract infections? A systematic review. $\mathrm{Br}$ Gen Pract. 2003;53(496):871-877.

11. de Vries SH, Raaijmakers R, Kranse R, Blijenberg BG, Schroder FH. Prostate cancer characteristics and prostate specific antigen change in screening detected patients initially treated with a watchful waiting policy. J Urol. 2004;172(6 Pt 1):2193-2196.

12. Kenter EG, Okkes IM, Oskam SK, Lamberts H. Tiredness in Dutch family practice. Data on patients complaining of and/or diagnosed with "tiredness." Fam Pract. 2003;20(4):434-440.

13. Hartley RM, Epstein AM, Harris CM, McNeil BJ. Differences in ambulatory test ordering in England and America. Role of doctors' beliefs and attitudes. Am J Med. 1987;82(3):513-517.

14. van der Weijden T, van Bokhoven MA, Dinant G-J, van Hasselt CM, Grol RP. Understanding laboratory testing in diagnostic uncertainty: a qualitative study in general practice. $\mathrm{Br} J$ Gen Pract. 2002;52(485):974-980

15. Prochazka AV, Lundahl K, Pearson W, Oboler SK, Anderson RJ. Support of evidence-based guidelines for the annual physical examination. A survey of primary care providers. Arch Intern Med. 2005;165(12):1347-1352.

16. Birbeck GL, Gifford DR, Song J, Belin TR, Mittman BS, Vickrey BG. Do malpractice concerns, payment mechanisms, and attitudes influence test-ordering decisions? Neurology. 2004;62(1):119-121.

17. Penchansky R, Macnee C. Initiation of medical malpractice suits: a conceptualization and test. Med Care. 1994;32(8):813-831.

18. Van Bokhoven MA, Pleunis-van Empel MCH, Koch H, Grol RPTM, Dinant G-J, Van der Weijden T. Why do patients want to have their blood tested? A qualitative study of patient expectations. BMC Fam Pract. 2006;7:75.

19. Kravitz RL, Bell RA, Azari R, Kelly-Reif S, Krupat E, Thom DH. Direct observation of requests for clinical services in office practice: what do patients want and do they get it? Arch Intern Med. 2003;163(14):1673-1681.

20. Peck BM, Ubel PA, Roter DL, et al. Do unmet expectations for specific tests, referrals, and new medications reduce patients' satisfaction? J Gen Intern Med. 2004;19(11):1080-1087.

21. Jung HP, Wensing M, Grol R. What makes a good general practitioner: do patients and doctors have different views? Br J Gen Pract. 1997;47(425):805-809.

22. Kravitz RL, Callahan EJ. Patients' perceptions of omitted examinations and tests. A qualitative analysis. J Gen Intern Med. 2000;15(1):38-45.

23. Kravitz RL, Callahan EJ, Paterniti D, Antonius D, Dunham M, Lewis CE. Prevalence and sources of patients' unmet expectations for care. Ann Intern Med. 1996;125(9):730-737.

24. Stalenhoef JGA. Resultaten NIPO-enquête 2006: Wat vinden huisartsen en patiënten van elkaar? Huisarts Wet. 2007;50(1):5.

25. Suchman AL, Roter D, Green M, Lipkin M Jr. Physician satisfaction with primary care office visits. The Collaborative Study Group of the American Academy on Physician and Patient. Med Care. 1993;31(12):1083-1092.
26. Jackson J, Kincey J, Fiddler M, Creed F, Tomenson B. Differences between out-patients with physical disease and those with medically unexplained symptoms with respect to patient satisfaction, emotional distress and illness perception. Br J Health Psychol. 2004;9(Pt 4):433-446.

27. Sitzia J, Wood N. Patient satisfaction: a review of issues and concepts. Soc Sci Med. 1997;45(12):1829-1843.

28. van Bokhoven MA, Koch $\mathrm{H}$, van der Weijden $\mathrm{T}$, Bindels PJE, Grol RPTM, Dinant G-J. Blood test ordering for unexplained complaints in general practice: the VAMPIRE randomised clinical trial protocol. BMC Fam Pract. 2006:7:20.

29. Garcia JA, Paterniti DA, Romano PS, Kravitz RL. Patient preferences for physician characteristics in university-based primary care clinics. Ethn Dis. 2003;13(2):259-267.

30. Murphy-Cullen CL, Larsen LC. Interaction between the socio-demographic variables of physicians and their patients: its impact upon patient satisfaction. Soc Sci Med. 1984;19(2):163-166.

31. Kvamme OJ, Sandvik L, Hjortdahl P. Praksisform, legekarakteristika og pasientvurdert kvalitet i norsk allmennpraksis. Tidsskr Nor Laegeforen. 2000;120(21):2499-2502.

32. Thompson SC, Nanni C, Schwankovsky L. Patient-oriented interventions to improve communication in a medical office visit. Health Psychol. 1990;9(4):390-404.

33. Koch H, Van Bokhoven MA, Ter Riet G-J, Van der Weijden T, Dinant GJ, Bindels P. The course of unexplained complaints in general prac tice. J Psychosom Res. 2006;61(3):419.

34. Hartz AJ, Noyes R, Bentler SE, Damiano PC, Willard JC, Momany ET. Unexplained symptoms in primary care: perspectives of doctors and patients. Gen Hosp Psychiatry. 2000;22(3):144-152.

35. van der Horst HE, Meijer JS, Muris JWM, et al. NHG-Standaard: Prikkelbare Darm Syndroom (irritable bowel syndrome). Huisarts Wet. 2001:44:58-65.

36. Salmon P, Peters S, Stanley I. Patients' perceptions of medical explanations for somatisation disorders: qualitative analysis. BMJ. 1999;318(7180):372-376.

37. Dowrick CF, Ring A, Humphris GM, Salmon P. Normalisation of unexplained symptoms by general practitioners: a functional typology. Br J Gen Pract. 2004;54(500):165-170.

38. Salmon P, Dowrick CF, Ring A, Humphris GM. Voiced but unheard agendas: qualitative analysis of the psychosocial cues that patients with unexplained symptoms present to general practitioners. $\mathrm{Br}$ J Gen Pract. 2004;54(500):171-176.

39. Ring A, Dowrick C, Humphris G, Salmon P. Do patients with unexplained physical symptoms pressurise general practitioners for somatic treatment? A qualitative study. BMJ. 2004;328(7447):1057.

40. Grol R, Whitfield M, de Maeseneer J, Mokkink H. Attitudes to risk taking in medical decision making among British, Dutch and Belgian general practitioners. Br J Gen Pract. 1990;40(333):134-136.

41. Stalenhoef JGA. Vragen over preventie in de NHG-enquêtes 1999 [Questions about prevention in the questionnaires of the Dutch College of General Practitioners 1999]. Huisarts Wet. 2000;43(4):196-197. 